\title{
Análisis de la seguridad Pública en el 2010
}

\author{
René Portillo Cuadra \\ Secretario General Utec
}

$\mathbf{E}$ Plan quinquenal 2010-2014 presentado por el Gobierno del presidente Mauricio Funes, sostiene que desde el inicio de la posguerra, nuestro país ha registrado elevados niveles de violencia e inseguridad, y por está razón ha sido considerado uno de los países más violentos de la región; sus tasas de homicidios superaban los 50 homicidios por cada cien mil habitantes. Estas cifras generan inseguridad en la ciudadanía y se convierten en uno de los principales problemas que enfrenta el país.

El citado Plan quinquenal señala como principales líneas de acción, en materia de control y represión del delito, las que a continuación se describen:

a) Combatir frontalmente la criminalidad en todas sus expresiones $y$, en especial, los delitos que más afectan a la ciudadanía;

b) Reducir la impunidad mediante el fortalecimiento de las instituciones del sector justicia encargadas de la investigación de los hechos delictivos y a través de la mejora de la coordinación interinstitucional;

c) Modernizar y profesionalizar la Policía Nacional Civil (PNC) en sus funciones de control y represión (gestión, disuasión, investigación criminal e inteligencia);

d) Elevar la calidad de la formación de la Academia Nacional de Seguridad Pública; y e) Fortalecer la seguridad migratoria.

No obstante definir una serie de planes de seguridad, acciones y estrategias para enfrentar los índices de criminalidad, El Salvador continua siendo uno de los países más inseguros del mundo. Los esfuerzos del Gobierno parecen no tener éxito. A continuación expondremos una serie de áreas en las que el gabinete de seguridad debe priorizar su trabajo:

\section{Desacuerdos en las estadísticas de los homicidios}

El Salvador, al igual que otros países de la región centroamericana, se caracterizan por no tener estadísticas centralizadas, creíbles y actualizadas de los hechos delictivos que se cometen

La PNC y la Fiscalía General de República (FGR) desconocen con certeza el porcentaje preciso de incidencia que tienen las pandillas en los homicidios que se registran en el país. El subdirector general de la PNC señaló "que la falta de un estudio pormenorizado que determine la vinculación exacta de grupos de pandillas en los homicidios, hace que estos se calculen a través de la práctica, que oscila entre el $40 \%$ y $50 \%$ de los crímenes".

En cambio, el Departamento de Estadísticas Forenses del Instituto de Medicina Legal (IML) sostiene que en 2009 solo 
el $11,8 \%$ de los homicidios estuvo vinculado a pandilleros.

La falta de un estudio técnico y metodológicamente elaborado y actualizado sobre los índices de la criminalidad es una deuda en El Salvador, lo cual es evidente, ya que esta información nace producto de la investigación del delito, -y como lo diremos más adelante- esta es una falencia medular en el problema del combate a la delincuencia.

\section{Inseguridad en el transporte colectivo}

En El Salvador es común amanecer sin transporte colectivo en una ciudad, colonia o barrio como medida de protesta por la muerte de empresarios, motoristas y cobradores de autobuses y microbuses, o por el cobro de la denominada "renta". Pero el paro al transporte colectivo a escala nacional producto de las amenazas de las maras o pandillas en la primera semana de septiembre (2010), fue un hecho que solo tuvo precedentes durante la guerra civil que vivió El Salvador en la década de los 80 .

Al paro del transporte colectivo se sumó el cierre de negocios en todo el país (no en un 100\%) y un "toque de muerte" promovido por las pandillas en las zonas de Mejicanos y sus alrededores, que provocó la movilización de tropa apoyadas con tanques y vehículos blindados en el gran San Salvador.

Aún cuando la presencia policial y militar fue notoria, la familia salvadoreña vivió -a nuestro juicio- uno de los momentos más dramáticos del 2010, por que, contra cualquier análisis, quedó demostrado el poder de incidencia de las pandillas en El Salvador.

La ciudadanía reprobó las medidas tomadas por el gabinete de seguridad para enfrentar el paro al transporte público. Ante la pregunta: ¿Avala las medidas tomadas por el gabinete de seguridad para hacerle frente al paro de transporte?, el $78 \%$ respondió no. Solo el 22\% respondió que sí.
Ante la pregunta: ¿Cree que el presidente debe pedir la renuncia del gabinete? El 61\% de los encuestados dijo sí y el $39 \%$ dijo no.

\section{Menores de edad victimas y victimarios en una sociedad violenta.}

De acuerdo con el PNUD, las principales expresiones de preocupación por los menores Centroamericanos, son:

1) Los homicidios de menores y su participación en actividades delictivas;

2) El abuso por parte de las autoridades;

3) El maltrato en el hogar;

4) Los abusos sexuales a los que están expuestos;

5) La explotación laboral; y

6) La explotación sexual de carácter comercial.

De acuerdo con los registros del Instituto Salvadoreño para el Desarrollo de la Niñez y la Adolescencia (ISNA) los casos de maltrato, abuso sexual y explotación sexual con fines comerciales, en niños y niñas, se ha incrementado en el país. El aumento se refleja en la comparación de estas mismas causas de ingresos con las de años pasados, para el caso:

Por maltrato y abuso sexual ingresó al el 19\% de menores al ISNA en 2007, el 20\% en 2008, y en 2009 ingresó un 18\%, y en lo que va del año, ya se superó el $20 \%$ de ingresos por estas causas.

La otra cara de una misma realidad expresa que el $60 \%$ de Ios delitos que se comenten, por ejemplo, en Santa Ana, (segundo departamento con mayor índice de violencia) son perpetrados por menores de edad. De acuerdo con datos 
policiales, el número de menores ligados a homicidios se ha duplicado, se trata de menores de entre 12 y 16 años, que son utilizados por las pandillas para cometer diversos delitos.

De enero a julio de 2009, en Santa Ana, se registró la detención de 234 menores por diversos delitos, mientras que en el mismo período de 2010 se capturaron 291, lo que representa un aumento del $24 \%$.

De acuerdo con datos del ISNA las pandillas reclutan a menores que habitan en las calles para que cometan delitos. De diez niños que deambulan por la calle, que ingresaron al ISNA, la mitad de ellos fueron localizados en inmuebles que ocupan las maras para delinquir. El ISNA detalló que estos jóvenes ya se identifican por medio de los códigos que utilizan las pandillas.

El diagnóstico que presenta la situación de los niños es de alta vulnerabilidad y riesgo. La desintegración familiar, la drogodependencia, la violencia doméstica y la falta de recursos económicos de los hogares salvadoreños son algunos detonantes de esta patología, que pareciera que no ha sido prioridad para la clase política y ni para los gobernantes, pues supone una respuesta basada en inversión adecuada para enfrentar el problema, y no sufrir en el futuro las consecuencias de esta irresponsabilidad estatal.

Funcionarios del Isna han sostenido que el problema en la atención integral de la niñez no radica en la falta de proyectos, sino en la ausencia de dinero para ejecutar dichos proyectos. No obstante lo anterior, se está elaborando un diagnóstico sobre la población infantil en las calles del gran San Salvador. Estos resultados estarían listos hasta marzo del 2011, y servirán para empezar a ejecutar los planes de prevención.

\section{La investigación de delito sigue siendo deficiente}

La obligación constitucional de dirigir la investigación del delito corresponde a la Fiscalía General de la República, para lo cual recibirá la colaboración de la Policía Nacional Civil (PNC). Concomitante a esta obligación, también corresponde a la Fiscalía promover la acción penal de oficio o a petición de parte, así lo establece el Art. 193 de la Constitución de la República.

Sin duda alguna, la PNC ha hecho esfuerzos por mejorar su capacidad de investigación, pero hay decisiones que parecen tardías y que debieron tomarse desde el inicio del mandato presidencial. Muestra de ello es que hasta el segundo semestre del año, la PNC establece como prioridad la creación de la División Central de Investigaciones, como parte de una reestructuración de la Subdirección de Investigaciones.

El subdirector de Investigaciones de la PNC ha expresado que la corporación necesita 600 nuevos investigadores para que se sumen a los 3.800 agentes dedicados a indagar homicidios, extorsiones, violaciones, entre otros delitos. Señaló el jefe policial que hay que esperar unos dos años para que estos nuevos investigadores cursen todo el protocolo que debe seguirse para convertirse en investigador.

\section{Armas de fuego sin control}

El Informe de Desarrollo Humano 2009-2010 del PNUD, expresa que en Centroamérica circulan cerca de tres millones de armas fuego y que dos de cada tres de ellas son ilegales. Guatemala, Honduras y El Salvador son los países con mayor número de armas ilegales.

En tal sentido, no es coincidencia que estos países también tengan el mayor número de homicidios cometidos con ar- 
mas de fuego. Expresa el PNUD que en El Salvador más de la mitad de la población estaría dispuesta a armarse para defenderse, aunque en su mayoría se oponen -en teoría- a las armas de fuego.

Solo en el oriente del país se han decomisado cerca de 1.500 armas de fuego, de estas el $20 \%$ eran propiedad de ciudadanos que las portaban para su defensa y el resto estaban en poder de delincuentes.

La PNC sostiene que hay un porcentaje de armas decomisadas que se comprobó científicamente que fueron usadas en delitos varios.

\section{La problemática en los centros penales}

El sistema penitenciario de El salvador ha colapsado, su capacidad instalada solo le permite albergar a 8.110 internos; sin embargo, al 30 de junio del presente año, se contabilizaban 23.840 internos, cantidad que triplica la capacidad de sus instalaciones.

De estos reclusos, 15.454 tienen la calidad de condenados, es decir, el 65\% de la población total; 8.386 aún están siendo procesados en los tribunales, cantidad que asciende al $35 \%$ de la población reclusa.

Los datos oficiales revelan que los centros penales con mayor saturación son: El Centro Penal de Mujeres en Ilopango, que tiene una población equivalente a siete veces más de su capacidad, le siguen los centros Penales La Esperanza en San Salvador, el penal de San Vicente y, por último, el de San Miguel.

Por otra parte, un total 1.500 elementos de la Fuerza Armada conforman la denominada "Fuerza de Tarea San Carlos", destinada a apoyar la seguridad penitenciara en las cárceles de máxima seguridad, colaborando en el registro de personas y seguridad periférica de los centros penales.

Como expresión del Plan de Seguridad anunciado por el presidente de la República -y más como una respuesta a la masacre de Mejicanos- la PNC y el ejército realizaron a finales de junio una megarequisa en los centros penales de Ciudad Barrios, San Miguel, Zacatecoluca, Chalatenango, San Francisco Gotera y en la penitenciaría de Izalco. Los resultados de esta sección, solo confirmaron la vulnerabilidad del sistema penitenciario y la falta de concreción de los fines para los que fueron creados los centros penales y de readaptación. De acuerdo con declaraciones del subdirector de Áreas Especializadas de la PNC, se decomisaron 189 porciones de droga, 430 punzones, 23 cuchillos, 22 teléfonos celulares, 33 chips, 17 baterías para teléfono y 12 cargadores, entre otros accesorios.

\section{Empresas de seguridad privada con poco control superan en número a los miembros de la PNC}

La División de Registro y Control de Servicios Privados de Seguridad cuenta con 27 policías para supervisar a más de 23.500 agentes de seguridad, que pertenecen a 209 agencias privadas de seguridad, más 14 asociaciones de vigilantes independientes que operan en El Salvador.

No obstante la exigua cantidad de miembros de dicha división, han realizado un trabajo de verificación que ha permitido detectar algunas irregularidades en las que incurren dichas empresas, tales como: pérdida de armas y municiones que no es denunciada ante las autoridades competentes; decomiso de armas de fuego por carecer de matrículas o con matrículas vencidas; algunas empresas están operando 
sin las autorizaciones de funcionamiento debidas. Por otra parte, cuando estas empresas cierran sus operaciones, no existe un control del destino de las armas utilizadas, ni tampoco reportan inventarios de estas a la PNC.

Una de las estrategias que está implantando la PNC para incrementar las inspecciones, es descentralizar la verificación por medio de las delegaciones en las que -en palabras del Jefe de la División- todavía hay que capacitar a los policías para que realicen esta labor.

\section{Ante esta problemática proponemos:}

- Acordar un pacto nacional en el que participen todos los partidos políticos, gremiales empresariales, representantes de sindicatos, agrupaciones del movimiento social, iglesias, universidades y Gobierno, a fin de establecer una agenda de aquellos problemas sociales en los que el consenso determine medidas mínimas de tratamiento y solución. Por consiguiente, no se trata de elaborar un documento y someterlo a la opinión pública, sino potenciar la coparticipación activa de todos los sectores.

- La depuración de los servidores públicos vinculados a actos de corrupción, abuso de autoridad u otro tipo de delitos o faltas de los que laboran en las instituciones que conforman el sistema de seguridad y justicia es impostergable. Instituciones y dependencias como: La PNC, FGR, jueces, traslado de reos y Dirección de Centros Penales, deben fortalecer sus oficinas internas de investigación de personal para corregir conductas reñidas con la actuación propia de estos servidores públicos, y, en caso de ser constitutivos de delito, dar aviso a la FGR para su correspondiente acusación.

- Actualmente la Ley Penitenciaria regula el trabajo de los internos "como un derecho y como un deber", no como una obligación, con lo cual se incentiva el ocio. La propuesta consiste en reformar algunas disposiciones de la Ley Penitenciaria para obligar a los internos a trabajar y/o a estudiar. El trabajo obligatorio para los internos no viola la Constitución, sino que es en una forma de readaptación y generación de ingresos para ellos, sus familias y para indemnizar a la victimas.

- Aprobar de forma inmediata la Ley de Peligrosidad, en la cual se tipificarían como conductas sujetas a sanción aspectos que no están considerados como delitos. Por otra parte, esta propuesta implica fusionar las faltas del Código Penal con esta nueva ley. Esta ley tendría un carácter preventivo y, a la vez, punitivo que permitiría bajar los índices de delincuencia en el país. 